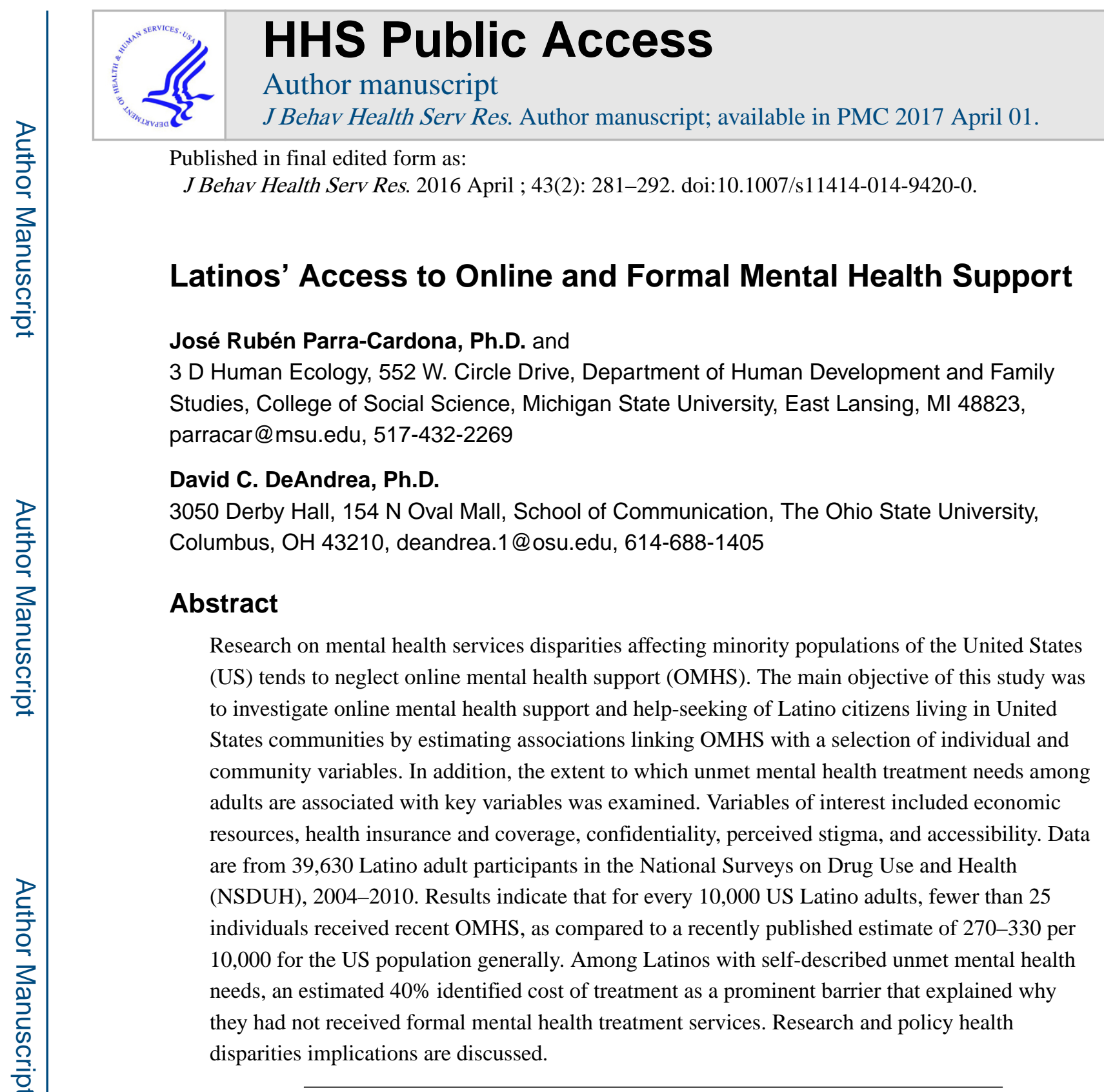

A recent investigation based on data from a nationally representative sample survey on Americans using online mental health social support services and peer-to-peer mental health venues such as online chat rooms show that 270 to 330 per 10,000 adults in the United States (US) have turned to this form of online mental health support (OMHS). ${ }^{1}$ Three noteworthy OMHS discoveries associated with this study reflect a 'digital divide' in relation to racial/ethnic minority health services disparities. First, in many subgroups (including Latinos), older adults are less likely to be recent OMHS users, as compared to young people. Second, this signal of a potential OMHS disparity was independent of family income. Third, college-educated adults were more likely to have engaged in OMHS activities. ${ }^{1}$

The current study seeks to extend this line of inquiry with a focus on Latino adults in the US national survey sample, with an expectation that among Latinos (as in the overall US adult population) the level of education will help account for recent OMHS activity. Nonetheless,

Conflict of interest The authors have no conflicts of interest to declare. 
an unknown is whether the education-OMHS association among Latinos is completely independent of a Latino preference for the English language, which has been used as an indicator of acculturation or ethnic identity, and instead deserves specific attention in OMHS disparities research. Thus, if online mental health services yield beneficial mental health outcomes, these services should be made available to Latinos who prefer (or only) speak Spanish. ${ }^{2}$ For this reason, the proposed working conceptual model for research on Latinos and OMHS includes Spanish language preference as a potential determinant, in addition to educational attainment.

Even though family income level has not been salient as a correlate of OMHS use, some evidence suggests that treatment costs might help account for failure to seek formal specialty care (i.e., in lieu of OMHS). ${ }^{1}$ Accordingly, the survey estimates address possibilities that treatment costs might account for unmet mental health services needs. Specifically, when no formal mental health services had been used, participants were asked to account for this apparently unmet need, and 'cost of treatment' was one response option. As such, this research report on Latino adults in the US will shed new light on these facets of mental and behavioral health services disparities.

By way of background for the present investigation, Latinos now constitute the largest ethnic minority group in the US. ${ }^{3}$ Although the overall health of the U.S. population has improved over the last two decades, ethnic minority populations continue to experience a disproportionate burden of neuropsychiatric and general medical illnesses. ${ }^{4,5}$ Among Latinos, first-generation low-income immigrant families often face intense contextual challenges such as language barriers, high levels of work demands, limited access to social and health care services, and social isolation. ${ }^{6,7}$ Historical exclusion and discrimination continue to prevent Latinos from accessing culturally relevant interventions that might buffer these contextual challenges and promote well-being. ${ }^{8}$ Some health disparities experienced by Latinos can be traced to the 'digital divide,' consisting of limited access to and use of the internet to improve health and mental health care. ${ }^{9}$ Strategic priority plans to address the digital divide are included in several US government action plans. ${ }^{10}$

\section{Health Disparities and the Digital Divide}

The Universal Service Fund (USF) was created by the United States Federal Communications Commission in 1997 to "make basic telecommunications services accessible to the public at reasonable and affordable costs." 11 As a result, researchers have confirmed that adequate internet access is associated with increased utilization of physical and mental health services, improved quality of decision-making to prevent and manage disease, reduced anxiety, increased feelings of self-efficacy, and a more active patient role in the treatment process. ${ }^{9}, 11,12$ These benefits are particularly relevant if internet-based resources can be used to reduce health disparities experienced by ethnically diverse and underserved populations. ${ }^{13,14}$

Promoting the use of technology to improve the delivery of physical and mental health care in the US has become a priority for the Department of Health and Human Services (HHS). Specifically, the 2004 HHS strategic plan on health information technology identifies 
information technology at the core of the agency's efforts to personalize health care (e.g., enhance informed consumer choices) and improve population health (e.g., accelerate dissemination of evidence). ${ }^{15}$

Despite the multiple benefits associated with internet-based health promotion, its associated benefits continue to be beyond the reach of a vast majority of Latino populations. ${ }^{14,16}$ According to the Pew Research Center, the percentage of Latino adults who are internet users $(73 \%)$ is similar to non-Latino Blacks $(74 \%)$ and lower than non-Latino Whites $(83 \%) .{ }^{17}$ Specific factors account for these disparities in internet utilization. Specifically, $78 \%$ of English-dominant Latinos and $76 \%$ of bilingual Latinos use the internet, compared to only $32 \%$ of Spanish-dominant Latinos. With respect to education, $89 \%$ of Latinos with a college degree access the internet, compared to $70 \%$ of Latinos who have completed high school, and only $31 \%$ of Latinos without a high school degree (Fox, 2007). With respect to income, $39 \%$ of Latinos with an annual household income less than $\$ 30,000$ use the internet. Age also constitutes a significant predictor of internet utilization among Latinos as $67 \%$ Latinos age $18-29$ go online, compared to $61 \%$ age $30-41,58 \%$ age $42-51,46 \%$ age $52-60$, $27 \%$ age $61-70$, and only $17 \%$ age 71 and older. Finally, low socio-economic status (SES) constitutes a significant barrier for Latinos. Whereas $43 \%$ of White adults have home broadband connections, the percentage is reduced to only $29 \%$ for Latinos. Of Latinos who do not go online, $53 \%$ state lack of access as the main barrier for utilization. ${ }^{2}$ In essence, the multiple barriers and challenges associated with the digital divide as experienced by Latinos in the US constitutes "a paradox in internet health information technology because it is available to all; yet, for a large segment of the US population, it is not within reach." 16

\section{Mental Health Disparities Experienced by Latinos}

In addition to disparities experienced through the digital divide, Latinos are less likely than non-Latino Whites to access formal mental health services despite the fact that both groups experience similar rates of mental health problems. ${ }^{17}, 18$ Furthermore, there is an increased occurrence of mental health and psychiatric disorders associated with Latinos' length of residence in the US. Among Latinos, demand for mental health services is expected to increase. ${ }^{19,20}$

Factors associated with lower utilization of formal mental health services among Latinos include low SES, higher reliance on the general medical health care sector (e.g., family medicine) than in specialty mental health care (e.g., psychiatry), and preference for utilizing multiple sources of care (e.g., folk healers, religious leaders) rather than one type of mental health professional (e.g., psychiatrists, psychologists). ${ }^{17,21}$ Of particular interest is the review of epidemiological studies on Latinos' mental health services conducted by Cabassa and colleagues, ${ }^{20}$ who identified lower levels of mental health care utilization among less acculturated Latinos resulting from cultural stigma associated with neuropsychiatric symptoms. Furthermore, barriers to access and lack of cultural competency in service delivery constitute additional barriers to adequate treatment. ${ }^{21}$

J Behav Health Serv Res. Author manuscript; available in PMC 2017 April 01. 


\section{Purpose of the Study}

The purpose of this study is to investigate online mental health support (OMHS) and helpseeking of Latino citizens living in United States communities by estimating associations linking OMHS with a selection of individual and community variables. A specific focus is participation in online mental health support groups or chat-rooms. In addition, analyses were conducted to examine the extent to which unmet mental health treatment needs among adults, including lack of access to formal services, are associated with key variables that are not frequently reported in the existing literature. For example, additional variables of interest in this study included stigma and confidentiality concerns, negative perceptions about treatment, and individual-level barriers (e.g. "seeking mental health treatment is inconvenient").

Analyses for this study are based entirely on data collected for the National Surveys of Drug Use and Health (NSDUH), 2004-2010. One important characteristic of the NSDUH is the fact that the survey allows respondents to identify specific factors that they believe have influenced their level of contact with the mental health system. ${ }^{22}$ This exploratory study's findings should contribute to a knowledge base needed to enhance technological solutions in efforts to reduce mental health disparities experienced by US Latino populations.

Furthermore, and based on the restrictions associated with the dataset utilized in this study, the terms OMHS in this investigation refers exclusively to internet support groups or chat rooms, excluding additional forms of OMHS.

\section{Methods}

\section{Study Population}

The annual NSDUH surveys have a study population designated to encompass civilian, noninstitutionalized US residents age 12 and older, including residents of households as well as group quarters and homeless shelters. Its nationally representative samples are drawn using multi-stage area probability sampling for each of the 50 states in the U.S. and the District of Columbia, with an allowance for probability sampling of residents in multiple dwelling units sampled within the same census tracts, and for probability sampling of multiple respondents within the same dwelling unit. These features of the 'complex' sample design are taken into account via survey analysis weights and via use of the calculus for variance estimation, as described below.

The NSDUH sampling frame is based on lists of non-institutional residential dwelling units within primary sampling units in all geographic areas under study. The surveys exclude relatively small segments of the current U.S. non-institutionalized population, such as homeless persons who do not reside in shelters, military personnel on active duty; residents of institutional group quarters such as prisons and psychiatric hospitals also are excluded. It is important to note that participation in the NSDUH is not restricted to drug users or to individuals with psychiatric or behavioral disorders. With the exceptions as just noted, all community-dwelling civilian residents are eligible to be sampled and to participate as survey respondents. Cognizant institutional review boards for human subject protection approve 
each year's NSDUH audio-enhanced computer-assisted self-interview assessment protocol (United States, 2012).

This research report's estimates are based on 39,630 Latino adult NSDUH participants during 2004 through 2010; the sample's 12-17 year olds are not asked OMHS survey items. Table 1 presents an overview of selected socio-demographic characteristics of these adult Latino survey participants, cross-classified by OMHS status, with unweighted numbers and subgroup proportions shown for the OMHS non-users, and with unweighted numbers shown for the 95 OMHS users. As shown, a slight majority of OMHS non-users self-identified as female $(52.7 \%)$ compared to those self-identified as male $(47.1 \%)$. The majority of these participants were 18-25 years of age (56.2\%), followed by 35-49 (18.5\%), 26-34 (18.2\%), and older than 50 years of age (7\%). Approximately forty three percent of these participants had annual income between $\$ 20,000-\$ 49,999$, followed by respondents with an annual income lower than $\$ 20,000$ (31.8\%). Approximately $24 \%$ of these participants had incomes higher than $\$ 50,000$. With regards to education, thirty six percent of respondents had not earned a high school degree, followed by completion of high school (32.1\%), some college education (22.4\%), and a college graduate education (9.2\%). Similar patterns were observed for OMHS users, with the exception of education as the highest number of OMHS respondents had some college education, followed by high school graduates, college graduates, and users with less than a high school degree.

\section{Assessment}

All participants have the option of completing the surveys in Spanish or English. As shown in Table 1, roughly $2 / 3$ rds of these respondents chose the English language interview $(68.8 \%)$, while a minority chose the Spanish language version (30.9\%). The interview module containing standardized mental health service questions is positioned midway through the NSDUH assessment. Via this module, all adults are provided a list of alternative mental health treatment options (including online support) and asked to indicate if they used any of these services in the past 12 months. Participants confirming the use of at least one form of alternative treatment are then asked to indicate if they used an Internet support group or chat room in the past 12 months 'for treatment, counseling, or support for problems with emotions, nerves, or mental health,' which has been used as a primary response variable in analyses (coded ' 1 ' for OMHS activity and ' 0 ' for no activity).

All adult respondents are also asked if, in the past 12 months, there was any time when they needed mental health counseling or treatment but did not get it. Participants are then presented with a list of explanations as to why they did not receive needed counseling or treatment. The list includes economic barriers, stigma concerns, fear of negative consequences in the workplace, limited information about mental health care providers, confidentiality concerns, health insurance limitations, and various contextual barriers (e.g., lack of transportation, childcare, etc.).

Standardized NSDUH items also assess socio-demographic characteristics of the type described in Table 1. One community variable based on the US Census is added to the dataset -- namely, population density of the area of residence. 


\section{Statistical Analysis}

A standard "explore, analyze/estimate, explore" cycle started with Tukey-style box-andwhisker plots and other exploratory data analyses to shed light on underlying distributions of the variables of interest. The next step was to estimate bivariate associations between helpseeking via OMHS and each characteristic under study. A multiple logistic regression model was then specified to estimate covariate-adjusted OMHS associations, with survey analysis weights and variance estimation as described below. Separately, contingency table analyses for weighted proportions were estimated for each possible explanation given when participants did not make use of mental health treatment services; these estimates are stratified by the language version of the survey taken (English or Spanish).

In this work, precision was stressed and focus on $95 \%$ confidence intervals (CI); $p$-values served as an aid to interpretation. All weighted analyses were conducted using Stata version 11.0. Stata 'svy' commands were used to account for the complex survey design, with standard NSDUH analysis weights (e.g., to account for variations in sample selection probabilities), with Taylor series linearization for variance estimates (i.e., to account for nonindependent observations due to features of the multi-stage sampling plan), and with subpopulation commands used to restrict analyses to Latino adults.

\section{Results}

Table 1 presents unweighted numbers and proportions in a description of basic characteristics of the NSDUH study sample. The final column of Table 1 displays OMHS estimates for each subgroup under study. To illustrate, an estimated 13 per 10,000 adult Latino males had engaged in at least one online mental health support activity during the 12 months prior to the date of assessment; the corresponding estimate for adult Latino females is 11 per 10,000 .

Table 2 shows odds ratio estimates for the strength of association linking each subgroup with recent OMHS activity, where the null odds ratio equals $1.0(\mathrm{OR}=1.0)$. Accordingly, congruent with Table 1's sex-specific proportions (13 per $10 \mathrm{~K}$ for males; 11 per $10 \mathrm{~K}$ for females), the estimate in the first row of Table 2 shows an OR of 0.9, with a 95\% CI that entraps the null OR value of $1.0(95 \% \mathrm{CI}=0.3,2.5)$.

Table 2 shows no association linking either respondent income or location of residence with recent OMHS activity, but noteworthy patterns became apparent in relation to choice of the Spanish language version of the NSDUH interview, as well as level of educational attainment. As shown in Table 2, Latino adults who chose the Spanish version of the assessment are less likely to seek online mental health social support, as indicated by an inverse odds ratio, with 95\% CI that do not entrap the null $\mathrm{OR}(\mathrm{OR}=0.2 ; 95 \% \mathrm{CI}=0.1,0.5$; $p<0.001)$. As compared to Latino adults who did not finish high school, those who earned a high school diploma but did not attend college were similar in their odds of OMHS activity, whereas those who had attended at least some college were more likely to have OMHS activity $(\mathrm{OR}=3.7 ; 95 \% \mathrm{CI}=1.0,13.1 ; \mathrm{p}=0.04)$. 
Close inspection disclosed a previously undetected pattern involving the combination of Spanish language choice and the highest levels of education, and motivated construction of a multiple logistic regression model to show occurrence of OMHS activity expressed as a function of age, sex, and sub-categories of participants formed by combining Spanish language choice with levels of education. This aggregate NSDUH sample of more than 39,000 Latino adults included some college-educated participants who chose the Spanish language interview, but none of these individuals had recent OMHS activity. This 'sampling zero' in the dataset prompted us to treat this sub-category as a separate sub-population, and to re-estimate odds ratios with a reference subgroup consisting of Latino adults who had not attended college and who chose the English language version of the interview. Via this additional analysis focused on participants who chose the English language version, a statistically robust association was found indicating that college educated Latinos (with or without a college degree) are more likely to have OMHS activity ( $\mathrm{OR}=3.0 ; 95 \% \mathrm{CI}=1.0$, 9.2; data not shown in a table). Among those who had not attended college, choice of the Spanish language interview was not associated with OMHS activity $(\mathrm{OR}=0.4 ; 95 \% \mathrm{CI}=$ $0.4,1.4$; data not shown in a table).

In the NSDUH sample data on the topic of unmet need for mental health services, an unweighted total of 2,013 Latino adults were identified who had unmet mental health services needs. The majority of these respondents chose the English language interview version ( $\mathrm{n}=1,733)$; only 280 chose the Spanish version. Only 95 out of 2,013 had recent online mental health support activity $(<0.1 \%)$. With respect to mental health services other than OMHS, 121 people $(6 \%)$ had been users of inpatient mental health services $(95 \% \mathrm{CI}=$ $0.04,0.08), 544$ people $(27 \%)$ had received outpatient consultations $(95 \% \mathrm{CI}=0.22,0.31)$, and $684(34 \%)$ had used prescribed medications for their mental health problems $(95 \% \mathrm{CI}=$ $0.30,0.39$ ). These estimates are not shown in a table.

Table 3 shows weighted proportions with respect to specific reasons for not obtaining needed help for mental health problems. Overall, approximately $40 \%(95 \% \mathrm{CI}=0.35,0.45)$ of Latino adults with unmet mental health treatment needs cited not being able to afford the cost of treatment as a prohibitive factor. Interestingly, roughly 5\% cited a lack of health coverage and roughly $10 \%$ cited an insufficient level of coverage as hindering factors. None of these proportions varied in relation to English versus Spanish interview choices. However, as indicated by the non-overlapping $95 \%$ confidence intervals reported in table 3, those taking the survey in English relative to those taking the survey in Spanish were more likely to be concerned about being committed or having to take medicine, that they didn't want others to find out that they needed treatment, that they were worried about the effect treatment might have on job performance, and that they didn't have the time. "Not knowing where to get services" is prominent reason cited across all Latino respondents as a barrier to meeting their mental health treatment services needs.

Table 4 shows a description of the occurrence of OMHS activity among Latinos with unmet needs for mental health treatment services, in the form of subgroup estimates for the proportion with recent OMHS activity. These results are exploratory due to the relatively small numerators for the proportions, which preclude the use of covariate-adjusted regression models to account for observed variations with sex and age. As shown in Table 4, 
among Latinos with unmet needs, the men were more likely than the women to have recent OMHS activity, and with respect to age, the young adults age 26-34 were more likely to be OMHS active. Other noteworthy estimates indicate that OMHS activity is more frequent among individuals who chose the English language version of the interview and among those residing in larger metropolitan areas. The occurrence of recent OMHS activity is least common among Latinos with lower levels of education than Latinos with some college attendance or completion of a college degree (Table 4).

\section{Discussion}

The main findings of this study may be summarized succinctly. First, Latino adults who chose the Spanish interview were less likely to have recent OMHS activity. Among Latinos who chose the English language version of the interview (often used as a marker of greater acculturation or assimilation within the US), those who had attended at least some college were more likely to be OMHS active, irrespective of whether a college degree had been earned. With regard to unmet mental health needs and access to services, $40 \%$ of participants identified cost of treatment as a prohibitive factor for seeking mental health services, although this barrier did not necessarily refer to a lack of health insurance. Specific barriers for treatment were also identified based on the language version of the survey.

Before detailed discussion of these results, important study limitations merit attention. First, within the large Latino sample, the sub-sample of OMHS-active adults turned out to be quite small, thwarting more detailed analyses. In addition, English versus Spanish language choice proved to be an essential control variable, leaving little room for detailed within-group comparisons (e.g., Mexican versus Cuban heritage or ethnic identification). In addition, the NSDUH is not designed for Latino research specifically. As such, the survey assessment lacks contextual variables that would help to analyze with more accuracy key life experiences pertinent to this population such as might be studied in focused research on acculturation and acculturative stress. Finally, because the NSDUH only captures internet support group and chat room participation, alternative forms of OMHS are not identified in the survey (e.g., self-help searches).

Notwithstanding limitations such as these, these findings and exploratory estimates provide empirical evidence on health services disparities in the OMHS domain and barriers to mental health treatment among Latinos. With regard to OMHS, it may not be surprising that higher levels of achieved education predict increased likelihood of OMHS help-seeking. More probing research may discover that degree of acculturation, ability to network, and a sense of empowerment subserve this college-OMHS association. ${ }^{12,23}$ Educational achievement is likely to enhance access to computers and the internet, as discovered in past digital divide research on barriers affecting ethnically diverse populations. ${ }^{11}$ Furthermore, limited literacy and inadequate computer training constitute important barriers among ethnic minority populations, including Latinos. ${ }^{24}$

The discovery that Spanish speaking Latinos were less likely to be OMHS help-seekers draws attention to past research on health services disparities in general, which has found evidence of disparities affecting Latino first-generation and low-income immigrants whose 
preferred language is Spanish. As previously stated, some health disparities experienced by Latinos can be traced to the 'digital divide,' which consists of limited access to and use of the internet to improve health and mental health care. ${ }^{9}$ Although strategic priority plans to address the digital divide are included in several US government action plans, ${ }^{10}$ important access barriers continue to prevent a large segment of Latinos in the US from benefiting from online mental health services. ${ }^{8}$

For example, in a study conducted with parents engaged in pediatric health care screening services, $44 \%$ of Spanish speaking parents had used computers to look for health or medical information, versus $60 \%$ of English speaking parents. ${ }^{14}$ When asked about their perceptions related to completing online pre-visit assessments, parents expressed concerns related to limited literacy, inability to use computers, lack of access to printers, and preferences for doing face-to-face or phone screenings. Thus, Latinos are affected by the digital divide based on language and literacy limitations, but also by key variables such as cultural preferences that privilege meaningful interpersonal relationships with service providers. ${ }^{22,} 25$

Furthermore, despite the fact that only $5 \%$ of participants cited lack of health insurance as a major barrier to access mental health treatment, an appreciable proportion of participants described treatment costs as a major deterrent to access services, irrespective of EnglishSpanish language choice. Even with the Affordable Care Act in place, poverty may continue to play a role in the barriers to mental health treatment services, ${ }^{26}$ if accessing services becomes prohibitive due to high deductibles, wide coverage exclusions, or high copayments. $^{27}$

This investigation provides insight on additional barriers to accessing mental health treatment based on the preferred language of respondents. For English speaking participants, concerns referred to being committed or having to take medicine, not wanting others to know that they needed treatment, worrying about effects on their jobs, and not having enough time. These findings confirm that fear of stigma and mistrust of institutions constitute salient deterrents to seeking mental health treatment. ${ }^{22}$ Thus, ethnic minorities may trust community clinics more than traditional health care institutions based on the increased cultural resonance that community clinics are likely offer. ${ }^{26}$ As it has been noted in the literature, "coverage without adequate providers is unlikely to decrease service disparities." 29

Finally, the participants who completed the survey in Spanish are likely to be most affected by access-related issues such as not having enough money, inadequate health coverage, and not knowing where to go for services. These unsolved problems continue to highlight the need to promote effective policy aimed at addressing Latino health disparities as previously outlined in the 2002 landmark report by the Institute of Medicine (IOM), Unequal

Treatment: Confronting Racial and Ethnic Disparities in Health Care. ${ }^{4}$ Specifically, policy is highly needed in order for providers to engage in efforts to promote health and mental services among Latinos by considering the important limitations that this population experiences such as limited access, language and financial barriers, and inadequate health coverage. As a transformative health care reform is being promoted with the Affordable Care Act, it is essential for service providers to acknowledge that "referral" to online health 
and mental services is not sufficient. Rather, policy is necessary to ensure that health and mental health care providers take into consideration for service provision, the multiple barriers commonly experienced by Latino populations, as they were documented in this survey. The need to address these pressing health disparities is urgent as findings from this exploratory OMHS project confirm the enduring nature of these unsolved problems.

\section{Implications for Behavioral Health}

Findings from this investigation have relevant behavioral health implications. First, despite recent advances in technology-related health care services and delivery, current data indicate that health care disparities continue to seriously affect Latino populations, particularly if they experience poverty and limited education. In this study, Spanish-speaking participants were identified as the Latino sub-group with the highest barriers to access mental health services as well as OMHS. In addition, regardless of the potential benefits associated with the recently approved health care reform, factors such as cost of treatment, confidentiality concerns, stigma, and accessibility continue to be major barriers to Latinos seeking to access mental health care. Thus, it will be critical to monitor in the upcoming implementation of the health care reform, the extent to which these barriers are effectively addressed. Finally, although the use of technology has been identified by the federal government for over two decades as a key alternative to improve the delivery of physical and mental health care in the US, Latinos and particularly Spanish-speaking Latinos, experience disproportionate disparities that prevent them from receiving the benefits associated with OMHS. Addressing this issue in all facets of health care delivery (e.g., prevention, treatment adherence) should become a top priority among health care organizations as the transition to electronic means of health care delivery is becoming a standard practice in the nation.

\section{Acknowledgments}

Supported in part by NIDA K05DA015799 (JCA), T32DA021129, R25DA030310, \& K01DA036747-01

\section{References}

1. DeAndrea DC, Anthony JC. Online peer support for mental health problems in the United States: 2004-2010. Psychological Medicine. 2013; 43(11):2277-2288. [PubMed: 23410539]

2. Fox, S. Latinos Online. Washington, DC: Pew Latino Center and Pew Internet Project; 2007.

3. U.S. Census Bureau. USA 2010 Quick Facts. United States Census Bureau: Available online at http://quickfacts.census.gov/qfd/states/00000.html. [Accessed November 3, 2012]

4. U.S. Department of Health and Human Services. [Accessed November 29, 2012] HHS Action Plan to Reduce Racial and Ethnic Health Disparities. Available online at http:// minorityhealth.hhs.gov/npa/templates/content/aspx?lvl=1\&1vlid=33\&ID=285.

5. National Institutes of Health. [Accessed November 1, 2012] National Institutes of Health Strategic Planning for Health Disparities Research. Available online at http//obssr.od.nih.gov/content/ strategic_planning.

6. Flores G, Olson L, Tomany-Korman SC. Racial and ethnic disparities in early childhood health and health care. Pediatrics. 2005; 115:183-193.

7. Ku L, Matani S. Left out: Immigrants access to health care and insurance. Health Affairs. 2001; 20(1):247-256. [PubMed: 11194848]

8. Castro FG, Barrera M, Pantin H, et al. Substance abuse prevention intervention research with Latino populations. Drug and Alcohol Dependence. 2006; 84:S29-S42. (S). [PubMed: 16787713] 
9. Suarez-Balcazar Y, Balcazar FE, Taylor-Ritzler T. Using the internet to conduct research with culturally diverse populations: Challenges and opportunities. Cultural Diversity \& Ethnic Minority Psychology. 2009; 15(1):96-104. [PubMed: 19209984]

10. U.S. Congressional Research Service. [Accessed September 25, 2013] Broadband internet access and the digital divde: Federal assistance programs. Available online at http://www.fas.org/sgp/crs/ misc/RL30719.pdf.

11. Lorence DP, Park H, Fox S. Racial disparities in health information access: Resilience of the digital divide. Journal of Medical Systems. 2006; 30(4):241-249. [PubMed: 16978003]

12. Ybarra ML, Suman M. Help seeking behavior and the internet: A national survey. International Journal of Medical Informatics. 2006; 75(1):29-41. [PubMed: 16129659]

13. Cotten SR, Gupta SS. Characteristics of online and offline health information seekers and factors that discriminate between them. Social Science \& Medicine. 2004; 59(9):1795-1806. [PubMed: 15312915]

14. Hambidge SJ, Phibbs S, Beck A, et al. Internet-based developmental screening: A digital divide between English- and Spanish-speaking parents. Pediatrics. 2011; 128(4):939-946.

15. U.S. Department of Health and Human Services. [Accessed June, 2013] The Decade of Health Information Technology: Delivering Consumer-centric and Information-rich Health Care. Available online at http://www.providersedge.com/ehdocs/ehr_articles/The_Decade_of_HITDelivering_Customer-centri_and_Info-rich.

16. Peña-Purcell N. Hispanics' use of the internet health information: An exploratory study. Journal of the Medical Library Association. 2008; 96(2):101-107. [PubMed: 18379664]

17. Pew Research Center. [Accessed January 3, 2013] Demographics of Internet Users. Available online at http://www.pewinternet.org/Trend-Data-\%28Adults\%29/Whos-Online.aspx.

18. Wang PS, Lane M, Olfson M, et al. Twelve-month use of mental health services in the United States. Archives of General Psychiatry. 2005; 62:629-640. [PubMed: 15939840]

19. Alegría M, Mulvaney-Day N, Torres M, et al. Prevalence of psychiatric disorders across Latino subgroups in the United States. American Journal of Public Health. 2007; 97(1):68-75. [PubMed: 17138910]

20. Cabassa LJ, Zayas LH, Hansen MC. Latino adults' Access to mental health care: A review of epidemiological studies. Administration and Policy in Mental Health. 2006; 33(3):316-330. [PubMed: 16598658]

21. Alegría M, Tekeuchi D, Canino G, et al. Considering context, place and culture: The national Latino and Asian American study. International Journal of Methods in Psychiatry Research. 2004; 13(4):208-220.

22. Ojeda VD, Bergstresser SM. Gender, race-ethnicity, and psychosocial barriers to mental health care: An examination of perceptions and attitudes among adults reporting unmet need. Journal of Health and Social Behavior. 2008; 49(3):317-334. [PubMed: 18771066]

23. Wang J, Bennett K, Probst J. Subdividing the digital divide: Differences in internet access and use among rural residents with medical limitations. Journal of Medical Internet Research. 2011; 13(1):e25. [PubMed: 21371989]

24. Sarkar U, Karter AJ, Liu JY, et al. Social disparities in internet patient portal use in diabetes: Evidence that the digital divide extends beyond access. Journal of the American Medical Informatics Association. 2012; 18(3):318-321. [PubMed: 21262921]

25. Wagner-Echegaray FA, Schütz CG, Chilcoat HD, et al. Degree of acculturation and the risk of crack cocaine smoking among Hispanic Americans. American Journal of Public Health. 1994; 84(11):1825-1827. [PubMed: 7977926]

26. Alegría M, Canino G, Ríos R, et al. Inequalities in use of specialty mental Health services among Latinos, African Americans, and non-Latino Whites. Psychiatric Services. 2002; 53(12):15471555. [PubMed: 12461214]

27. Driscoll AK, Bernstein AB. Health and access to care among employed and unemployed adults: United States, 2009-2010. National Center for Health Statistics Data Brief. 2012; 83:1-8. [PubMed: 22617552] 
29. Alegría M, Lin J, Chen C. The impact of insurance coverage in diminishing racial and ethnic disparities in behavioral health services. Health Services Research. 2012; 47(3):1322-1344. [PubMed: 22568675] 


\section{Table 1}

Selected characteristics of adult Latino respondents $(n=39,630)$. Unweighted numbers and proportions from the United States National Surveys on Drug Use and Health, 2004-2010.

\begin{tabular}{|c|c|c|c|}
\hline & \multicolumn{2}{|c|}{$\begin{array}{l}\text { Unweighted Numbers of Adults Who } \\
\text { Did and Did Not Use Online Support }\end{array}$} & \multirow{2}{*}{$\begin{array}{c}\text { Weighted Proportion } \\
\text { Using Online Support } \\
\begin{array}{c}\text { Estimated Number per } \\
\mathbf{1 0 , 0 0 0} \text { Adults }\end{array}\end{array}$} \\
\hline & $\begin{array}{l}\text { No OMHS Use } \\
\text { n }(\%)^{*}\end{array}$ & $\underset{n}{\text { OMHS Users }}$ & \\
\hline \multicolumn{4}{|l|}{ Sex } \\
\hline Male & $18,659(47.1)$ & 27 & 13 \\
\hline Female & $20,876(52.7)$ & 68 & 11 \\
\hline \multicolumn{4}{|l|}{ Age } \\
\hline $18-25$ & $22,237(56.1)$ & 58 & 6 \\
\hline $26-34$ & $7,193(18.1)$ & 16 & 10 \\
\hline $35-49$ & $7,327(18.4)$ & 16 & 6 \\
\hline $50+$ & $2,778(7.0)$ & 5 & 3 \\
\hline \multicolumn{4}{|l|}{ Income } \\
\hline Less than $\$ 20,000$ & $12,614(31.8)$ & 30 & 5 \\
\hline$\$ 20,000-\$ 49,999$ & $17,177(43.3)$ & 39 & 11 \\
\hline$\$ 50,000-\$ 74,999$ & $4,924(12.4)$ & 12 & 4 \\
\hline$\$ 75,000$ or more & $4,820(12.2)$ & 14 & 5 \\
\hline \multicolumn{4}{|l|}{ Education } \\
\hline Less than high school & $14,314(36.1)$ & 14 & 5 \\
\hline High school graduate & $12,705(32.1)$ & 29 & 4 \\
\hline Some college & $8,889(22.4)$ & 37 & 10 \\
\hline College graduate & $3,627(9.2)$ & 15 & 6 \\
\hline \multicolumn{4}{|l|}{ Language Choice } \\
\hline English & $27,280(68.8)$ & 84 & 22 \\
\hline Spanish & $12,255(30.9)$ & 11 & 2 \\
\hline \multicolumn{4}{|l|}{ Population Density } \\
\hline Metro area with $\geq 1$ million & $23,147(58.4)$ & 57 & 16 \\
\hline Metro area with $<1$ million & $14,815(37.4)$ & 37 & 9 \\
\hline Not in Metro area & $1,573(4.0)$ & 1 & N/A \\
\hline
\end{tabular}

The column $\%$ do not sum to $100 \%$ for each variable, due to rounding and OMHS use. 


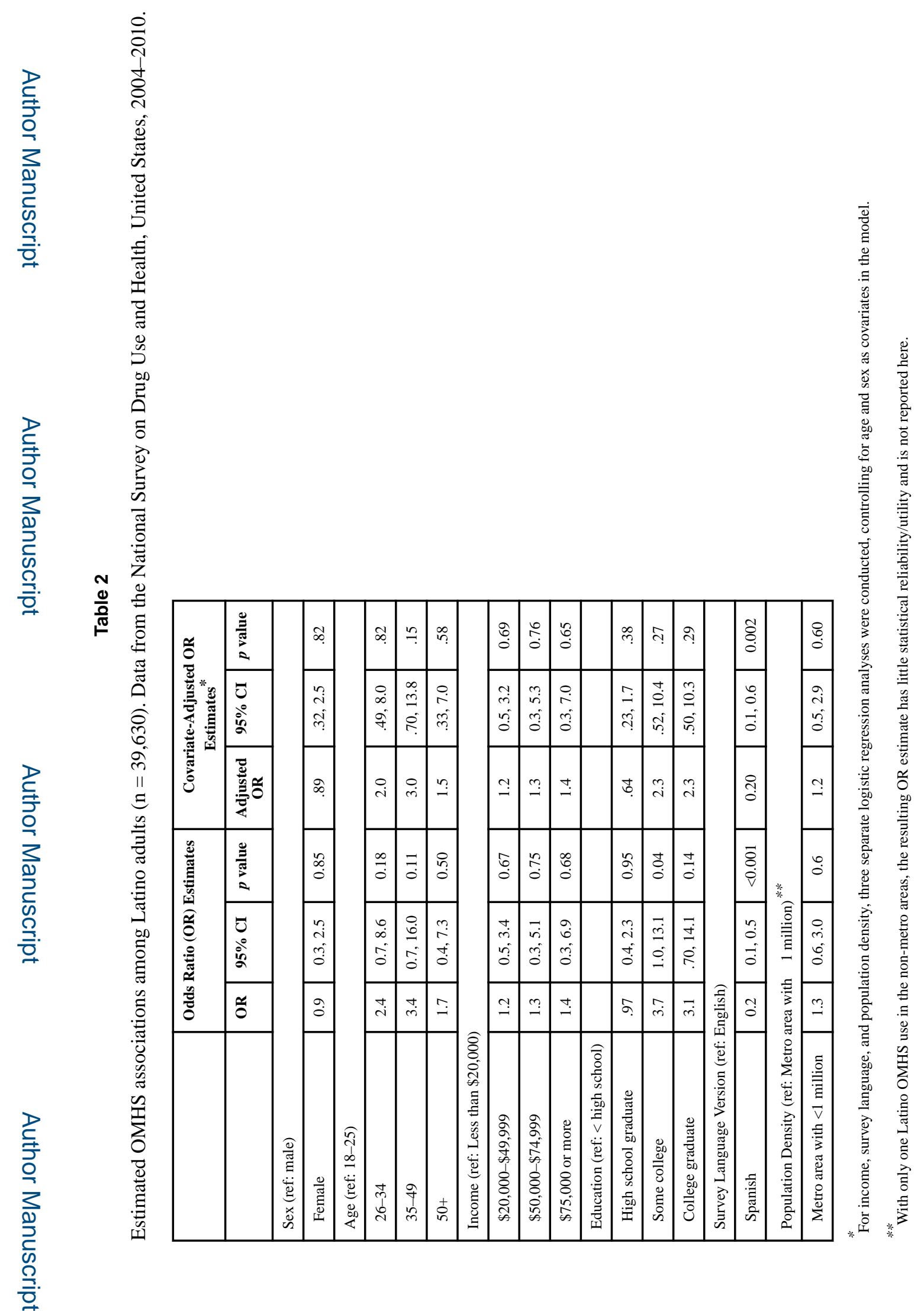

J Behav Health Serv Res. Author manuscript; available in PMC 2017 April 01. 


\section{Table 3}

Weighted proportions (95\% CI) of Latino adults citing specific reasons for unmet mental health treatment needs, stratified by choice of English versus Spanish language version of the interview. Data from the National Survey on Drug Use and Health, United States, 2004-2010.

\begin{tabular}{|l|c|c|c|}
\hline $\begin{array}{l}\text { Reason for not seeking } \\
\text { treatment services }\end{array}$ & $\begin{array}{c}\text { All Latino Adults } \\
\text { with Unmet Need } \\
(\mathbf{n = 2 , 0 1 3 )}\end{array}$ & $\begin{array}{c}\text { Unmet Need \& } \\
\text { English language } \\
\mathbf{c h o i c e} \\
(\mathbf{n = 1 , 7 3 3 )}\end{array}$ & $\begin{array}{c}\text { Unmet Need \& } \\
\text { Spanish language } \\
\text { choice } \\
(\mathbf{n}=\mathbf{2 8 0})\end{array}$ \\
\hline Not enough money & $.40(.35, .45)$ & $.41(.36, .46)$ & $.36(.24, .50)$ \\
\hline No health insurance & $.05(.04, .07)$ & $.06(.04, .08)$ & $.02(.01, .05)$ \\
\hline Not enough health coverage & $.09(.07, .12)$ & $.09(.07, .12)$ & $.10(.03, .30)$ \\
\hline Worried about negative community opinions & $.09(.07, .12)$ & $.10(.07, .13)$ & $.06(.02, .15)$ \\
\hline Concerned about treatment confidentiality & $.10(.07, .13)$ & $.12(.08, .16)$ & $.01(.002, .08)$ \\
\hline Worried about being committed or having to take medicine & $.10(.08, .14)$ & $.12(.09, .16)$ & $.03(.01, .08)$ \\
\hline Worried others would find out about treatment & $.06(.04, .08)$ & $.07(.05, .10)$ & $.001(.0001, .003)$ \\
\hline Worried about effect on job & $.08(.05, .11)$ & $.09(.06, .12)$ & $.01(.004, .04)$ \\
\hline Didn't know where to go for services & $.19(.16, .23)$ & $.19(.15, .24)$ & $.19(.11, .31)$ \\
\hline Didn't think treatment would help & $.07(.05, .10)$ & $.08(.06, .12)$ & $.002(.001, .007)$ \\
\hline No transportation, too inconvenient & $.03(.02, .05)$ & $.04(.03, .05)$ & $.02(.006, .05)$ \\
\hline Didn't have time & $.10(.08, .13)$ & $.12(.09, .15)$ & $.02(.006, .08)$ \\
\hline$*$ \\
Because participants were allowed to mark more than one reason, these column-wise proportions do not sum to 100\%.
\end{tabular}




\section{Table 4}

Selected characteristics of adult Latino respondents with unmet mental health needs $(n=2,013)$. Data from the National Survey on Drug Use and Health, United States, 2004-2010.

\begin{tabular}{|c|c|c|c|}
\hline & \multicolumn{2}{|c|}{$\begin{array}{l}\text { Unweighted \# of Adults Who Did or } \\
\text { Did Not Use Online Support }\end{array}$} & \multirow{2}{*}{$\begin{array}{c}\text { Weighted Proportion } \\
\text { Using Online Support } \\
\text { Estimated \# per } \\
10,000 \text { adults }\end{array}$} \\
\hline & $\begin{array}{l}\text { Did Not Use } \\
\text { n }(\%)^{*}\end{array}$ & $\begin{array}{l}\text { Did Use } \\
\text { n(\%) }\end{array}$ & \\
\hline \multicolumn{4}{|l|}{ Sex } \\
\hline Male & $622(30.9)$ & 12 & 200 \\
\hline Female & $1,343(66.7)$ & 36 & 136 \\
\hline \multicolumn{4}{|l|}{ Age } \\
\hline $18-25$ & $1,319(65.5)$ & 28 & 45 \\
\hline $26-34$ & $298(14.8)$ & 8 & 188 \\
\hline $35-49$ & $281(13.9)$ & 10 & 111 \\
\hline $50+$ & $67(3.3)$ & 2 & 28 \\
\hline \multicolumn{4}{|l|}{ Income } \\
\hline Less than $\$ 20,000$ & $737(36.6)$ & 19 & 77 \\
\hline$\$ 20,000-\$ 49,999$ & $782(38.8)$ & 15 & 152 \\
\hline$\$ 50,000-\$ 74,999$ & $218(10.8)$ & 6 & 52 \\
\hline$\$ 75,000$ or more & $228(11.3)$ & 8 & 90 \\
\hline \multicolumn{4}{|l|}{ Education } \\
\hline Less than high school & $573(28.5)$ & 6 & 61 \\
\hline High school graduate & $610(30.3)$ & 8 & 23 \\
\hline Some college & $575(28.6)$ & 24 & 178 \\
\hline College graduate & $207(10.3)$ & 10 & 110 \\
\hline \multicolumn{4}{|l|}{ Survey Language Version } \\
\hline English & $1688(83.8)$ & 45 & 367 \\
\hline Spanish & $277(13.8)$ & 3 & 5 \\
\hline \multicolumn{4}{|l|}{ Population Density } \\
\hline Metro area with $\geq 1$ million & $1,084(53.9)$ & 33 & 249 \\
\hline Metro area with $<1$ million & $791(39.3)$ & 15 & 123 \\
\hline Not in a Metro area & $90(4.5)$ & 0 & N/A \\
\hline
\end{tabular}

The column $\%$ do not sum to $100 \%$ for each variable, due to rounding and OMHS use. 